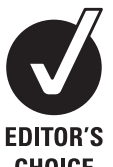

CHOICE
${ }^{1}$ Royal Bolton Hospital, Farnworth, Bolton, UK 2Blackpool Victoria Hospital, Blackpool, Lancashire, UK

\section{Correspondence to}

Dr David Jonathan Ahearn, Royal Bolton Hospital, Minerva Road, Farnworth, Bolton BL4 OJR, UK; davidjahearn@gmail.com

Received 19 August 2009 Accepted 29 November 2009

\title{
Improving end of life care for nursing home residents: an analysis of hospital mortality and readmission rates
}

\author{
D J Ahearn, ${ }^{1}$ T B Jackson, ${ }^{1} \mathrm{~J}$ Mcllmoyle, ${ }^{2}$ A J Weatherburn ${ }^{2}$
}

\begin{abstract}
Introduction Despite concern that many nursing home residents who become acutely unwell are admitted to hospital for often futile and distressing treatment, no previous studies analysing survival and readmission rates of this cohort were found in the literature.

Objective To study survival and readmission rates of nursing home patients admitted acutely to general medicine.
\end{abstract}

Method Analysis of all admissions to the acute medical unit of a busy district general hospital over a 94 day period, comparing nursing home residents with all admitted patients aged over 70 years.

Results Nursing home residents were significantly less likely to survive the admission than elderly people living in the community. $33.9 \%$ of nursing home residents did not survive the admission and $51.6 \%$ died within 6 weeks of admission. Of those discharged alive, $41.5 \%$ were readmitted or died within 6 weeks. Patients with a higher level of comorbidity were less likely to survive the admission or live to 6 weeks.

Discussion These findings raise the need for careful 'advance care planning'. This should become commonplace for nursing home residents to improve end of life care and reduce hospital admissions in patients unlikely to survive. The judicious use of 'Preferred Priorities for Care' documents, 'do-not-hospitalise' orders, and the establishment of a dedicated multidisciplinary team involving primary and secondary care is proposed to help achieve these aims.

Conclusion Survival rates in nursing home residents admitted to an acute medical unit are low, and measures are suggested to reduce inappropriate admissions and facilitate improved end of life care.

\section{INTRODUCTION}

It is of concern that many nursing home residents who become acutely unwell are sent to hospital for futile and often distressing treatment. ${ }^{1}$ It has been documented that the patients most likely to be admitted from a nursing home to hospital are the most physically frail. ${ }^{2}$ In many cases, palliation and comfort care in a familiar environment might be considered a desirable alternative more in-keeping with the nursing home resident's own wishes. ${ }^{3}$

The UK government has pledged to improve choice in both treatment and place of care for all patients nearing end of life. It has highlighted nursing and care homes as a key area for improving end of life care, with a focus on people with all chronic disease not limited to cancer. ${ }^{4}$
Initiatives such as the National Health Service Gold Standards Framework ${ }^{5}$ exist to improve care at the end of life (box 1). The framework is part of the NHS End of Life care programme and provides prognostic indicators for identification of patients with advanced illness in several different chronic disease areas.

Other documents such as the Preferred Priorities for Care $^{6}$ (formerly Preferred Place of Care) attempt to reduce the number of acute admissions that result in death, but these have had limited use in care home patients and are most frequently offered to patients with a cancer diagnosis.

Despite the considerable interest and concern in this area, little research or published work focuses specifically on the issues surrounding acute admission of patients from nursing homes to hospital. Previous work in the USA found at least two-fifths of hospital admissions of nursing home residents to be 'inappropriate'.

We found no published work documenting survival and readmission rates of patients admitted to hospital from long stay nursing homes. The objectives for our study were to calculate these data for the nursing home population admitted to the acute medical unit of a large district general hospital (box 2) in northern England.

Our primary objective was to calculate death in hospital, death at 6 weeks from initial admission, and readmission to hospital of those discharged within 6 weeks of the initial admission. Secondary goals included assessing whether a simple system of grading comorbidity correlates with the primary outcomes, and also calculating what proportion of admitted nursing home residents develop a new diagnosis during their admission-for example, hospital acquired infection.

\section{METHOD}

\section{Sample and inclusion/exclusion criteria}

We analysed the admissions to the medical unit of Blackpool Victoria Hospital over a 94 day period between 2 April 2007 and 4 July 2007. Only those patients living indefinitely in long term nursing institutions were included. Those in residential, respite or rehabilitation placements were excluded. Only acute admissions were included; one patient who attended regularly for semi-elective blood transfusions was excluded.

\section{Identification of patients}

The admissions books of the medical admissions unit and every medical ward were scrutinised a minimum of once a week; hospital databases 
Box 1 Stated purpose and aims of the Gold Standards Framework in Care Homes

\section{Purpose}

This is a framework to enable care homes to deliver a 'gold standard' of care for all people nearing the end of their lives. 'It's about living well until you die'.

Aims

1. To improve the quality of care provided for all residents from admission to the home.

2. To improve the collaboration with GPs, primary care teams and specialists.

3. To reduce the number of hospital admissions in the final stage of life, enabling more to die with dignity in the home, if that is their wish.

were cross-referenced where necessary. Patients from nursing homes were identified from their addresses; if there was any doubt their addresses and postcodes were cross-referenced with the social services list of nursing homes in the area. On a number of occasions where homes were dual registered (ie, had patients registered for both residential and nursing clients) we contacted the home to ensure the patient was from a nursing bed. Every patient episode during the study period was examined in this way and we feel confident we identified all the acute admissions of patients from nursing homes to general medicine during the study period.

\section{Sources of data}

Notes were analysed where available on the ward and requested if the patient had died or been discharged. Clinical information was taken from nursing home/general practitioner (GP) transfer documentation, patients' case notes and computerised documentation including discharge letters and notifications of death.

Information about length of stay and dates of death were accessed from hospital records and the NHS Strategic Tracing Service, allowing information about deaths out of hospital or readmissions to be recorded.

Identification of readmission information was obtained by reentering patients' hospital details into the hospital computer systems and the NHS Strategic Tracing Service.

\section{Data collection}

The data from transfer documentation and hospital clinical notes were extracted by two of the investigators (DA and TJ). A paper based proforma was used to collect the data listed in box 3 .

\section{Data analysis}

To allow comparison of the outcomes of patients with differing levels of comorbidity (ie, those diagnoses known about before the current admission), we designed a simple method involving groups of diagnoses in patients' past medical history (table 1). Patients would be recorded as belonging to a group if they had

\section{Box 2 Details of the acute medical unit of Blackpool} Victoria Hospital

Population served: 329800

Acute medical beds: 301

Acute admissions-all ages above 16 (2008): 14,844
Box 3 Information collection from patients' transfer documentation and hospital notes

Date of admission

Date of discharge (as appropriate)

Date of death (as appropriate)

Referral method, that is, via GP, 999 call by nursing home, etc

Age of patient

Gender of patient

any of the diseases listed before the acute illness. (If a patient had more than one diagnosis in a given group they would still only be recorded as belonging to the group once). So, for example, if a patient had a history of myocardial infarction and dementia, he or she would be recorded as having diagnoses in two groups, but a different patient with a history of only myocardial infarction and cardiac failure would be recorded as having diagnoses in only one group. Only established diagnoses made before the acute admission were included.

We compared the length of stay and proportion of deaths during hospital admission with a comparator group of All admissions to general medicine aged 70 or over'. Although we included patients of any age who were admitted from nursing homes, the majority were elderly. We felt using 70 years as a lower cut-off point provided a representative comparator group to allow us to analyse whether those admitted from a nursing home were more/less likely to die during that admission than community dwelling elderly people. The mean ages of patients in both groups were similar.

\section{Statistical methods}

The information was entered into Microsoft Excel 2007 12.0.4518.1014 and analysed using the sort, AVERAGE and STDEV functions. Odds ratios (OR), confidence intervals (CI) and $\mathrm{p}$ values were calculated using Medcalc Version 10.4.8.0.

\section{RESULTS}

Demographic, lengths of stay, mortality data, and level of comorbidity before the acute illness was obtained for $100 \%$ of patients. Information regarding diagnoses at death or discharge was obtained for $91.9 \%$ of admissions.

Table 1 Diagnoses included in each comorbidity group

\begin{tabular}{ll}
\hline Comorbidity group & $\begin{array}{l}\text { Confirmed diagnoses in past } \\
\text { medical history }\end{array}$ \\
\hline Cardiovascular and diabetes mellitus & Myocardial infarction \\
& Angina/ischaemic heart disease \\
& Cardiac failure \\
& Atrial fibrillation \\
& Hypertension \\
& Valvular heart disease \\
& Diabetes mellitus \\
Respiratory & Chronic obstructive pulmonary disease \\
& Pulmonary fibrosis \\
Neurological & Bronchiectasis \\
& Parkinson's disease \\
Psychiatric & Multiple sclerosis \\
& Stroke \\
Malignancy & Depression (on medication) \\
\hline
\end{tabular}


Table 2 Comparison of patients admitted to the medical unit (all admissions and those $\geq 70$ years) with those from nursing homes

\begin{tabular}{|c|c|c|}
\hline & $\begin{array}{l}\text { Admissions from } \\
\text { nursing homes }\end{array}$ & $\begin{array}{l}\text { All admissions to general } \\
\text { medicine aged } \geq 70 \text { years }\end{array}$ \\
\hline Number of admissions & 62 & 1884 \\
\hline \multicolumn{3}{|l|}{ Gender } \\
\hline Male & $30(48.4 \%)$ & $817(43.5 \%)$ \\
\hline Female & $32(51.6 \%)$ & 1067 (56.6\%) \\
\hline Age range & $47-98$ & $70-106$ \\
\hline Median age & 76 & 81.5 \\
\hline Mean age $\pm S D$ & $79.73 \pm 10.29$ & $81.59 \pm 6.83$ \\
\hline Died in hospital & $21(33.9 \%)$ & $295(15.7 \%)$ \\
\hline $\begin{array}{l}\text { After mean days } \\
\pm S D\end{array}$ & $8.48 \pm 8.82$ & $19.19 \pm 23.38$ \\
\hline After median days & 5 & 11 \\
\hline Range & 1 to 29 & 0 to 131 \\
\hline $\begin{array}{l}\text { Discharged to } \\
\text { same NH }\end{array}$ & $41(66.1 \%)$ & $\mathrm{n} / \mathrm{a}$ \\
\hline $\begin{array}{l}\text { After mean days } \\
\pm S D\end{array}$ & $10.12 \pm 9.86$ & $\mathrm{n} / \mathrm{a}$ \\
\hline After median days & 7 & $\mathrm{n} / \mathrm{a}$ \\
\hline Range of days & $1-46$ & $\mathrm{n} / \mathrm{a}$ \\
\hline \multicolumn{3}{|c|}{ Length of stay of all patients (deaths + those discharged alive) } \\
\hline Mean \pm SD & $9.56 \pm 9.48$ & $9.39 \pm 12.63$ \\
\hline Median & 5 & 6 \\
\hline Range & $1-46$ & $0-117$ \\
\hline
\end{tabular}

*Excluding patients transferred for inpatient rehabilitation.

\section{Comparison of those admitted from a nursing home with community dwelling elderly people}

Of the 3518 patients admitted to the acute medical unit over the 94 day period, there were 62 admissions from nursing homes, representing $1.76 \%$ of the total. Table 2 compares the demographics, outcomes and length of stay of these patients with those of all admissions to general medicine over the age of 70 years.

The proportion of those admitted from a nursing home that died during the admission was significantly higher when compared to patients in the category of 'all admitted patients over 70 years old' (21/62 vs $295 / 1884$ (33.9\% vs $15.7 \%)$, OR 2.76 , $95 \%$ CI 1.6 to $4.7, p=0.0002)$. The median time from admission to death was shorter in the first group than the second, occurring after a median of 5 days and 11 days, respectively.

\section{Subgroup analysis of those admitted from a nursing home}

Table 3 analyses just those patients admitted from a nursing home. Eleven of 41 (26.8\%) of patients who were discharged back to their nursing home were recorded to have died within 6 weeks of their hospital admission date; $6 / 41(14.6 \%)$ were recorded as having been readmitted by the same date.

When these figures are combined, it is calculated that over half $(32 / 62(51.6 \%))$ of those patients admitted from a nursing home died within 6 weeks of admission either in or out of hospital. The figures are higher, but not significantly so, for those admitted via their GP than those admitted via the accident and emergency department (A\&E) (18/33 (54.6\%) vs 14/29 (48.3\%), OR 1.29, $95 \%$ CI 0.47 to $3.49, p=0.6223)$. There was no significant difference between males and females $(16 / 30(53.3 \%)$ vs $16 / 32$ (50.0\%), OR $1.14,95 \%$ CI 0.42 to $3.10, p=0.7930)$, or between those over 80 versus those under $80(18 / 34(52.9 \%)$ vs $14 / 28$ (50.0\%), OR $1.13,95 \%$ CI 0.41 to $3.06, p=0.8176)$.

Comparing those with more extensive pre-admission comorbidity (diagnoses in three or four groups) with patients with lesser past medical history (diagnoses in only zero or one groups), it is clear that the patients in the former group were significantly more likely to die during the admission $(8 / 10(80.0 \%)$ vs $6 / 25$ (24.0\%), OR 12.67, 95\% CI 2.09 to $76.70, p=0.0057)$, or have died within 6 weeks of admission ( $9 / 10(90.0 \%)$ vs $9 / 25(36.0 \%)$, OR $16.00,95 \%$ CI 1.74 to $147.55, \mathrm{p}=0.014)$

Patients discharged back to their nursing home were more likely to be readmitted if they were male than female, although this do not reach statistical significance $(6 / 21(28.6 \%)$ vs $0 / 20$ $(0.0 \%)$, OR $17.19,95 \%$ CI 0.90 to $328.89, p=0.0589)$. There was also a similar trend in those under 80 but this again did not reach statistical significance $(5 / 19(26.3 \%) \vee 1 / 22(4.6 \%)$, OR $7.50,95 \%$ CI 0.79 to $71.23, \mathrm{p}=0.0794)$.

Table 3 Comparison of the admitted nursing home residents broken down by subgroup

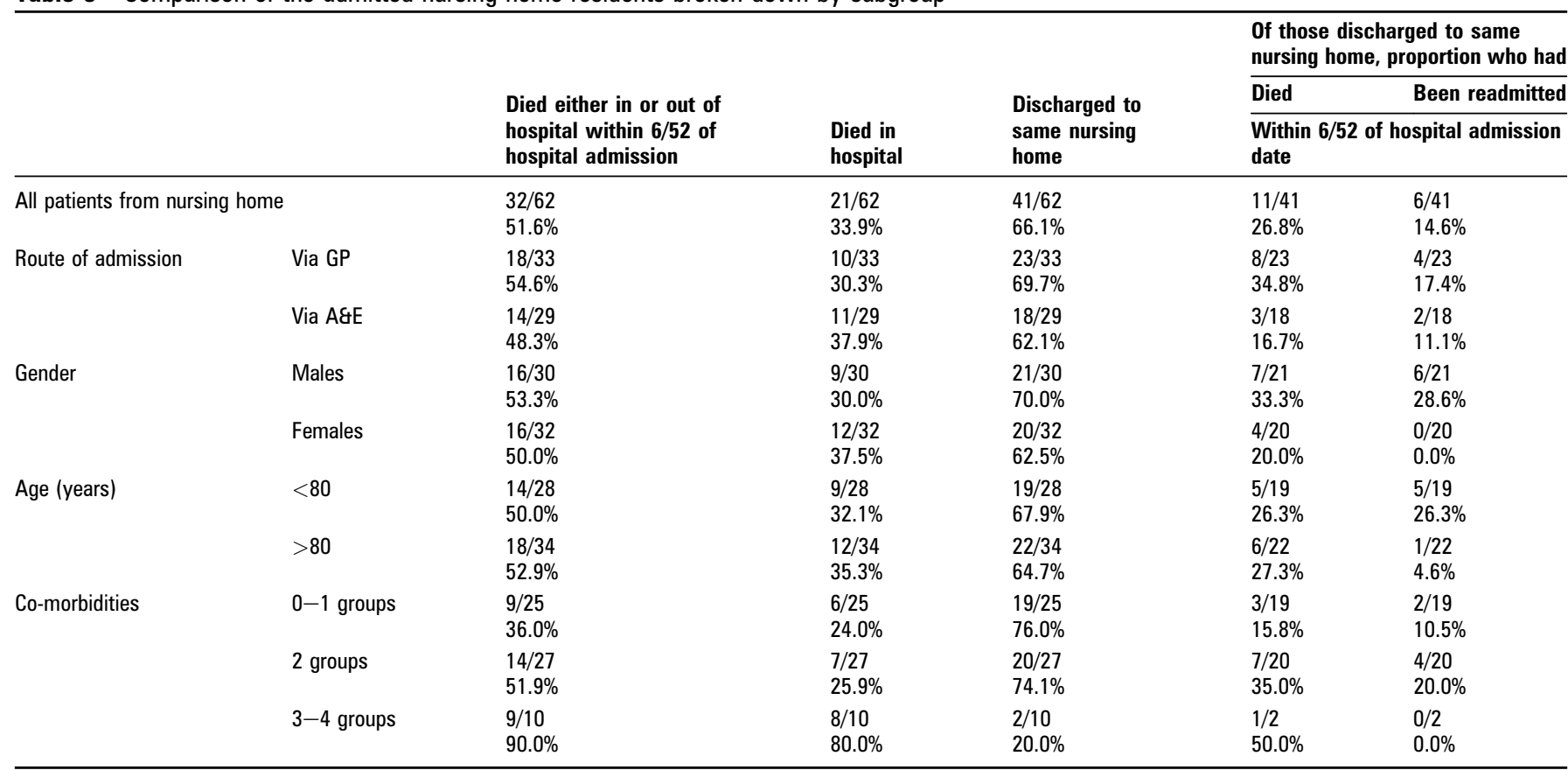




\section{Acquisition of new medical problems acquired in hospital}

Where a judgement could comfortably be made from case notes, it was deemed that in only two out of 38 cases $(5.26 \%)$ was a patient found to have acquired a new medical problem during their admission-for example, a hospital acquired infection.

\section{DISCUSSION}

Our results show that death and readmission rates of nursing home residents admitted to hospital with acute medical illness are high. Over one third of this group died during that admission-this being significantly higher than the comparator group. Over half of nursing home residents does not survive to 6 weeks from their admission. This suggests it may have been in the best interests of many of these residents to be palliated in familiar surroundings rather than being admitted to hospital for investigations and interventions that provide short lived benefits. In many cases admission may simply be extending the dying process at the cost of potentially uncomfortable, frightening and costly hospital admissions. ${ }^{8}$

\section{Clinical implications}

Our findings raise the issue of advance care planning for residents of nursing homes. This is a process where important decisions regarding certain aspects of end of life care are decided before any acute decline. ${ }^{9}$ This process should involve the patient where capacity allows. Although this is currently the source of much discussion, we feel that it is seldom implemented, particularly within the nursing home sector. National guidance on advance care planning has recently been published to advise health professionals. ${ }^{10}$ This covers all aspects of advance care planning including advance decisions to refuse treatment.

The Gold Standards Framework (GSF) is the NHS's flagship programme to improve end of life care. It recognises the needs for improved advance care planning in nursing and residential home patients in particular. Since 2004 the programme has developed a three stage training programme culminating in a 'Quality Hallmark Award' for accredited homes. This focuses on comprehensive 'pre-planning' for all residents and includes the specific aim of a reduction in unnecessary hospital admissions. Evaluation of the earlier forms of this scheme has resulted in positive feedback from both families and care home staff. There has been no formal evaluation on the effect of GSF implementation on numbers of acute hospital admissions. ${ }^{11}$

The identification of patients approaching end of life remains a difficult area and the GSF offers clinical prognostic indicators for patients likely to be nearing the last $6-12$ months of life. ${ }^{12}$ Work has focused particularly on cancer, organ failure, and elderly frailty/dementia as the main 'end of life patient groups'. Other prognostic scores have also been produced for this purpose but require further work. ${ }^{13}$ A less complex trigger suggested in the GSF is to simply ask the question 'Would you be surprised if this patient were to die in the next 6-12 months?' although this recommendation is not yet validated.

There remains reluctance among some healthcare staff to discuss advance care planning with patients and families, particularly when such issues have not been raised previously. This communication is key to success in advance care planning. Teamwork between medical staff, allied professionals and families has been highlighted as a pre-requisite for achievement of good end of life care in nursing homes. ${ }^{14}$

One mechanism for improving communication between nursing home residents, families and healthcare providers is
Box 4 The three questions on a preferred priorities for care form

Your preferences and priorities

1. In relation to your health, what has been happening to you?

2. What are your preferences and priorities for your future care?

3. Where would you like to be cared for in the future?

completion of a 'Preferred Priorities for Care' document. ${ }^{6}$ This allows residents who are mentally capable to record in a simple but formal manner their 'Preferences and Priorities' in the context of end of life care (box 4). Pilot work in the care home sector has shown promising results.

In our experience, 'do not hospitalise' orders are only very rarely considered or implemented in appropriate patients. These are advance directives put in place if it is felt that hospital admission in the event of acute illness would not be beneficial. ${ }^{15}$ The decision should be made before any acute, potentially hospitalising illness. A competent nursing home resident may make this decision him or herself. Alternatively, where this is not possible or considered appropriate, a physician in partnership with the family/carers may make it.

There are several models currently implemented in the UK which aim to improve end of life care for nursing home residents. ${ }^{16}$ A suggested model is the implementation of a primary care team of GPs, pharmacists and dedicated nursing staff who would provide input to care homes. An interface would occur with a consultant geriatrician in secondary care who would visit patients in their own care home or review them in a community clinic. A training programme for care home staff, including education on end of life issues, would be a key part of the programme. Multidisciplinary meetings could occur in care homes with patients, carers and relatives to discuss end of life issues and decisions on future hospitalisation.

\section{Future directions for research}

Identifying the subgroup of nursing home residents who have least to gain from hospital admission in the event of acute illness is difficult and would likely prove controversial. Our simple method of grouping patients by level of comorbidity shows that

\section{Main messages}

Many nursing home residents find acute admission distressing, many hospital admissions are 'inappropriate', and advance care planning can improve patients' end of life care.

- Nursing home residents were significantly less likely to survive acute medical admission than elderly people living in the community.

- The results show one third of nursing home residents did not survive the admission and over a half had died within 6 weeks of admission.

- Patients with a higher level of comorbidity are less likely to survive the admission or to 6 weeks than those with lower levels.

- Advance care planning should be considered in all nursing home residents, especially those with the greatest level of comorbidity. 


\section{Current research questions}

To ascertain any further factors other than medical comorbidity that have a correlation with outcome following acute admission to hospital.

- To identify which nursing home residents are at highest risk of deterioration and would consequently benefit most from advance care planning.

- To expand the evidence base for the components of advance care planning.

those with a higher level of pre-existing illness are more likely to die in hospital or have died 6 weeks from admission compared to those patients with less comorbidity. However, this is oversimplified and does not take into account disability or functional impairment of activities of daily living. Further research is needed in this area to identify more accurately this subgroup. One method might be a score which combines a functional element (eg, Barthel scale) together with a component which weights certain key conditions in a patient's past medical history (eg, severe Alzheimer's dementia or metastatic cancer) over seemingly less serious conditions (eg, hypertension).

\section{CONCLUSION}

We have shown that nursing home residents are significantly less likely to survive emergency admission to hospital with an acute medical illness than elderly people living in the community. In our sample, one-third of nursing home residents did not survive the admission and over half died within 6 weeks of the admission date. It can be argued that, in many cases, it would be in the best interests of these patients to provide palliation in the familiar surroundings of their own nursing home rather than undergo a futile and potentially distressing hospital admission. We have demonstrated that patients with higher levels of comorbidity are less likely to survive admission, but more work is needed to identify those patients who have least to gain from being hospitalised. The use of advance care planning should become commonplace for nursing home residents and we have made suggestions to help improve end of life care.

Contributors DA and TJ collected and analysed the data. DA wrote the manuscript with input from other authors. AW supervised the project. JM provided the original idea.

\section{Competing interests None.}

Ethics approval Submitted to and approved by Trust Research and Development Department.

Provenance and peer review Not commissioned; externally peer reviewed.

\section{REFERENCES}

1. Partridge J. Why are nursing home residents sent in to hospital to die? Postgrad Med J 2008;84:281. doi: 10.1136/pgmj.2008.070656.

2. Fried TR, Mor V. Frailty and hospitalization of long-term stay nursing home residents. J Am Geriatr Soc 1997;45:378-9.

3. Hays JC, Galanos AN, Palmer TA, et al. Preference for place of death in a continuing care retirement community. Gerontologist 2001;41:123-8.

4. Building on the best: choice, responsiveness and equity in the NHS Department of Health. 2003. http://www.dh.gov.uk/en/Publicationsandstatistics/Publications/ PublicationsPolicyAndGuidance/DH 4075292 (accessed 19 Aug 2009).

5. Gold Standards Framework. Gold Standards Framework in Care Homes. http:// www.goldstandardsframework.nhs.uk/GSFCareHomes (accessed 19 Aug 2009)

6. NHS National End of Life Care Programme. Preferred Priorities for Care (PPC) page of the NHS National End of Life Care Programme website. http://www. endoflifecareforadults.nhs.uk/eolc/ppc.htm (accessed 19 Aug 2009).

7. Saliba D, Kington R, Buchanan J, et al. Appropriateness of the decision to transfer nursing facility residents to the hospital. J Am Geriatr Soc 2000;48:154-63.

8. Purdy W. Nursing home to emergency room? The troubling last transfer. Hastings Cent Rep 2002;32:6.

9. NHS National End of Life Care Programme. Advance Care Planning. NHS National End of Life Care Programme. http://www.endoflifecareforadults.nhs.uk/eolc/files/ F2023-EoLC-ACP_guide_for_staff-Aug2008.pdf (accessed 19 Aug 2009).

10. Advance care planning. Concise guidance to good practice series, No 12. London: RCP, 2009. http://www.rcplondon.ac.uk/pubs/contents/9c95f6ea-c57e-4db8-bd98fc12ba31c8fe.pdf (accessed 19 Aug 2009).

11. Badger $\mathbf{F}$, Thomas $K$, Clifford $C$. Raising standards for elderly people dying in care homes. European Journal of Palliative Care 2007;14:238-41.

12. Gold Standards Framework. Prognostic indicator guidance. http://www. goldstandardsframework.nhs.uk/Resources/Gold\%20Standards\%20Framework/ PIG_Paper Final revised v5_Sept08.pdf (accessed 19 Aug 2009).

13. Flacker J⿳亠丷⿵冂丶 established long-term care residents. J Am Geriatr Soc 1998;46:1012-15.

14. Hewison A, Badger F, Clifford C, et al. Delivering 'Gold Standards' in end-of-life care in care homes: a question of teamwork? J Clin Nurs 2009;18:1756-65.

15. Dobalian A. Nursing facility compliance with do-not-hospitalize orders. Gerontologist 2004;44:159.

16. Donald IP, Gladman J, Conroy S, et al. Care home medicine in the UK-in from the cold. Age \& Ageing 2008;37:618-20. 